\section{“Ortega, profeta del destino latinoamericano: la identidad como 'autenticidad'"}

Roberto Aras*

\begin{abstract}
Resumen: Desde su primer viaje a América, el filósofo español José Ortega y Gasset ejerció una "jefatura espiritual" sobre el pensamiento incipiente de los nuevos pueblos transatlánticos. En especial, la relación con la Argentina y los argentinos le permitió actuar como un agente catalizador en la interrogación respecto del propio ser y su misión en el mundo. Los ensayos de psicología del argentino y su demanda de "autenticidad" a la hora de imaginar un futuro nacional y regional lo sitúan como un intelectual precursor en el problema de la identidad latinoamericana, cuya influencia sobre las mentes de filósofos, sociólogos, historiadores y literatos de estas tierras se deja observar hasta nuestros días.
\end{abstract}

Palabras clave: Argentina - de Imaz - Etchecopar - Gaos - identidad - Latinoamérica Marías - Ortega y Gasset - Pico - Zea.

[Resúmenes en inglés y portugués en la página 36]

(*) Doctor en Filosofía (Universidad de Navarra, 2004). Licenciado en Filosofía (UCA, 1987). Profesor Titular Ordinario en la Pontificia Universidad Católica Argentina en el Instituto de Ciencias Políticas (ICPRI) y en el Instituto de Comunicación Social (ICOS). Secretario Académico de la Facultad de Ciencias Sociales, Políticas y de la Comunicación de la Universidad Católica Argentina.

“...conviene tener presente esta ley tan perogrullesca como rigorosa: en la Historia sólo triunfa lo auténtico."

Rectificación de la República $(1931)^{1}$

En el tiempo apenas posterior al primer Centenario, comienza a discutirse entre la intelectualidad de Buenos Aires el problema de la identidad nacional2 ${ }^{2}$. La consolidación política y económica del país, y los primeros efectos sociales de la inmigración recibida durante el siglo XIX instalaron la cuestión con cierto dramatismo, pues "la Argentina era entonces más urbanizada que Bélgica e Inglaterra, los países más industrializados de la época" (Carballo, 2010, p. 28). Leopoldo Lugones, Ricardo Rojas y otros hombres de cultura se abocaron a la tarea de intervenir en la conciencia pública para ensayar caminos de integración 
y de consolidación nacional. Sin embargo, "el acelerado proceso de modernización económica, con la consecuente modificación de las estructuras sociales, no resultó acompañado por la creación de las instituciones políticas igualmente modernizadas" (Carballo, 2010, p. 61). Las grandes fortunas familiares consagradas a un estilo de vida europeo en la ciudad capital, por un lado, y la población rural diseminada en las extensiones inabarcables del interior, por otro, habían instalado una dualidad que amenazaba con perpetuarse. Los inmigrantes llegaban para asegurarse la prosperidad que no encontraban en su tierra natal e inyectaban en la comunidad local una avidez por el dinero que desplazaba cualquier interés cívico. La educación, la salud pública y el transporte estaban a la altura de cualquier urbe europea y la circulación de libros y periódicos atestiguaba el interés por participar de lleno en los circuitos ilustrados del mundo. Con similar entusiasmo se recibían visitas de prestigiosos científicos, literatos y pensadores que compartían sus conocimientos desde la tribuna universitaria o dictando conferencias en instituciones de la sociedad civil.

Precisamente, en este complejo escenario en el que se cruzaban las esperanzas más optimistas con los desafíos diarios para validar un proyecto común de convivencia desembarcaba en el puerto de Buenos Aires un joven filósofo español, José Ortega y Gasset (con apenas 33 años). Transcurría el mes de julio del año 1916. A partir de ese momento se sucederían dos visitas más, en 1928 y 1939, que marcarían el apogeo y la declinación de un vínculo con la Argentina siempre sincero y, por eso quizás, a veces áspero y hasta doloroso. Su interés por la Argentina ya se había iniciado algún tiempo antes, en España, cuando imaginaba la pampa, la llanura interminable, y se interrogaba por su «significado sentimental» ${ }^{3}$. A su llegada, la lectura de la Revista de Filosofía dirigida por José Ingenieros le permitió conocer las ideas positivistas que, por entonces, recorrían las aulas de la Facultad de Filosofía y Letras ${ }^{4}$ y sobre las que ofrecería una dura crítica, pertrechado con los argumentos neokantianos y los principios de la Fenomenología abrevados poco antes en Alemania. Pero ambas experiencias serían sólo el incentivo para comenzar una labor más profunda de rectificación del alma nacional a la que se dedicaría de lleno ejerciendo una «jefatura espiritual» 5 sin precedentes.

Sin embargo, los escritos de "psicología del argentino» -tal el caso de "La pampa...promesas" o "El hombre a la defensiva"-, revelaban una preocupación mayor que la simple caracterización temperamental. Establecían un horizonte de sentido, de valor y de descubrimiento de las posibilidades de realización que anidaban en el alma criolla.

América, en toda su prolongada geografía, era el continente de la esperanza, del «no ser todavía», del «futuro»; palabras de Hegel $^{6}$ a las que adhería Ortega pero bien que en un contexto diferente y con un propósito moralizador. "Muy especialmente Centro y SudAmérica, es para nuestra vieja y melancólica sensibilidad metropolitana un enérgico canto de vida y esperanza, como canta Rubén Darío, el indio divino" (Ortega y Gasset, I, p. 470). Se trataba pues de encontrar en el Muevo Mundo lo mejor de las aspiraciones europeas pero no para ejecutar aquí una copia de modos ajenos de vivir y de pensar, sino para alcanzar la consumación universal de un proyecto humanista7. "«Tú eres mi mejor yo» piensa Europa de América, cuando se reconcentra en sí misma allá en las meditaciones de alguno de sus filósofos o historiadores"8 señala Ortega (Ortega y Gasset, I, p. 470) -para marcar aquel propósito compartido. 
Ahora bien, para alcanzarlo desarrolla Ortega un programa que consta de dos acciones fundamentales: la primera, tomar conciencia de la necesidad de generar un conocimiento profundo de los resortes vitales del hombre americano y, la segunda, desarrollar la concepción integral de un complejo panhispánico que, al tiempo de vivificar a España en su misión histórica, habilitase a los pueblos criollos para alcanzar su identidad desde una interpretación original de la existencia americana.

Al primer momento hay que adscribir los variados textos sobre la psicología del argentino ya citados, entre los cuales, el siguiente párrafo es una magnífica síntesis:

Es preciso llamar al argentino al fondo auténtico de sí mismo, retraerle a la disciplina rigorosa de ser sí mismo, de sumirse en el duro quehacer propuesto por su individual destino. Sólo así podrá modificarse la moral colectiva, el tipo de valores preferidos, el standard de virtudes y modos de ser que, prestigiados, informen con fértil automatismo la existencia argentina ${ }^{9}$ (Ortega y Gasset, IV, p. 305).

Es indudable que la introspección resultaba un momento necesario para lograr una salida de sí que fuera, al mismo tiempo, sincera y convocante. Pero lo más interesante es que Ortega realizaba ese llamado no como un extranjero al paso que se inmiscuía en los asuntos de otro país sino desde un "perspectivismo americano» 10 conquistado por la frecuentación del alma criolla y robustecido por el ejercicio de una cátedra periodística que lo mantenía en contacto con su auditorio argentino. Es cierto que esta cruzada en pos de la revelación de la anatomía más íntima del ser nacional supuso desnudar al hombre argentino exteriorizando un repertorio de cualidades, muchas de ellas francamente negativas, que justificaban -a juicio de Ortega- el comportamiento colectivo del país. Para citar sólo las principales, habría que mencionar el innato narcisismo; la falta de solidaridad con la hora presente («futurismo»); la artificialidad de la vida, expresada en la máscara del rótulo social que suplanta al verdadero yo; la precariedad ostentada en todos los compromisos; el temor al ridículo con el consecuente repliegue defensivo sobre sí mismo, refractario de todo contacto sincero; la agresividad; la impertinencia; la exageración y la propensión a la burla.

Muchas de esas notas las condensaba Ortega en la noción de «guarango», una sugerente etiqueta que proponía para aplicar al argentino falto de límites, en la cual rescataba, sin embargo, la convicción de sentirse llamado a un destino superior.

La reacción que provocaron las páginas que contenían tal descripción fue épica. Desde las principales revistas culturales y los periódicos de circulación nacional aparecieron voces para «corregir» o, al menos, matizar, el diagnóstico orteguiano. Así, se sucedieron para marcar el territorio de lo tolerable para nuestro «amor propio», las páginas de Roberto F. Giusti (en la revista Nosotros), Manuel Gálvez (en el suplemento del diario La Nación), Emilio Coni, Raúl Scalabrini Ortiz (en su libro El hombre que está solo y espera), Ernesto Giraldez, Lucas Maldonado, Juan Álvarez (en el diario La Prensa) y Tina Spangerberg (del diario La Razón). Todos coincidían en apuntar críticas y establecer las deficiencias de los textos del filósofo español, no sin reconocer -a regañadientes- que algunos de los rasgos de la argentinidad presentados tenían plena vigencia. 
Ahora bien, a esta primera respuesta lanzada por una generación de escritores y periodistas, le siguió otra que supo encontrar en las palabras de Ortega la denuncia de un destino dramático oculto en el seno de la prosperidad económica y el progreso sostenido de la sociedad porteña. Ezequiel Martínez Estrada en su Radiografía de la pampa (1933) y Eduardo Mallea con Historia de una pasión argentina (1937) se apropiaron de la matriz de pensamiento orteguiana y ofrecieron una reflexión autóctona sobre los puntos sobresalientes detectados una década atrás por el insigne español. Ahora la cuestión se trasladaba del individuo a la sociedad toda; como dice Leo Pollmann sobre el libro de Martínez Estrada: "Es la obra de un autor que está a la búsqueda de la realidad interior y de los motivos inconscientes que rigen y mueven la realidad social"11(Martínez Estrada, 1993, pp. 450-451). Sin embargo, a causa de la polémica, orientada más a rechazar los adjetivos que a comprender la intención de los ensayos de Ortega, se pasó por alto una dimensión esencial de sus palabras: la apelación moral. En el entendimiento de que, a través del hombre medio analizado era posible alcanzar a la sociedad en su conjunto, Ortega proponía -después del diagnóstico- una praxis de alto contenido histórico y político. Por eso no hay que confundirse respecto del significado de la expresión «moral», pues en su filosofía tiene el fondo aristotélico que connota la perfección buscada por el hombre para su propia vida, que es la vida personal pero también la que transcurre en la polis.

Aquí es cuando aparece, luego del momento negativo, destructivo, del reconocimiento de las limitaciones constitutivas y de las aspiraciones insatisfechas, la gesta propicia para la vertebración del cuerpo nacional hacia el cumplimiento de su destino histórico, exigido por aquella demanda de autenticidad. Se trata, pues, de un proyecto «moral» en sentido estricto, por cuanto implica la elevación hacia el ideal de realización que ya estaba inscripto en las entrañas de la nacionalidad. De ahí que podamos repetir con José Lasaga que Ortega interpreta la «autenticidad» "como una invitación a ponderar lo que se es en realidad con lo que se es en proyecto" (Lasaga, 2006, p. 196).

Las consecuencias de ese enfoque son múltiples. Por una parte, había que asegurar que el punto de partida fuese suficientemente firme para soportar los esfuerzos reclamados por la misión de ser "el gran pueblo director de Sudamérica"12. Ello no se lograría sin ser capaces de una extrema «autenticidad», la cual, a los ojos de Ortega, involucraba a su vez, una enorme dosis de pragmatismo, capaz de abandonar las falsas utopías y concentrarse en la metódica cimentación del porvenir. Con justicia, entonces, reclamaba:

Nada urge tanto en Sudamérica como una general estrangulación del énfasis. Hay que ir a las cosas, hay que ir a las cosas, sin más.

(...)

Son ustedes más sensibles que precisos, y, mientras esto no varíe, dependerán ustedes íntegramente de Europa en el orden intelectual ${ }^{13}$ (Ortega y Gasset, II, p. 428). 
A la independencia política era imperioso, pues, sumar la independencia intelectual. Por otra parte, la «autenticidad» debía asumir, además de los rasgos etno-psicológicos del hombre medio, la condición misma de América en lo que Ortega calificaba como «estadio colonial», imprescindible para una determinación desde la filosofía de la historia del trayecto futuro de los pueblos criollos:

Por eso, en medio de grandes aciertos, considero un error que Keyserling se coloque ante América del Norte o América del Sur e intente decirnos lo que son, como si se tratase de pueblos viejos, cuyo espíritu es ya macizo y vive desde el centro radical de sí mismo. Este error le lleva a tomar como rasgos característicos modos transitorios y mostrencos de la vida colonial. (...) No; todavía no se puede definir el ser americano por la sencilla razón de que aún no es, aún no ha puesto irrevocablemente su existencia a un naipe, es decir, a un modo de ser hombre determinado. Aún no ha empezado su historia. Vive la prehistoria de sí mismo. Y en la prehistoria no hay protagonistas, no hay destino particular, domina la pura circunstancia. América no ha sido hasta ahora el nombre de un pueblo o de varios pueblos, sino que es el nombre de una situación, de un estadio: la situación y el estadio coloniales $^{14}$ (Ortega y Gasset, V, p. 44).

Y, ¿por qué le interesaba a Ortega este rasgo? "La dinámica colonial despertaba en Ortega una gran fascinación porque invertía la dinámica del tiempo de los fundadores de estas patrias republicanas" (Campomar, 2004a, p. 153), es decir, se trataba de pueblos «jóvenes» pero fundados por «viejos» europeos que en la transposición de sus patrias se renovaban y adquirían una edad nueva. Esa falta de «densidad histórica» era el origen de muchas de las características señaladas. En la medida en que los pueblos sudamericanos se sintieran parte de la misma línea temporal con España aquel vacío vendría a completarse y la identidad de las naciones hispanoamericanas resultaría rescatada de las rupturas caprichosas que las dejaban sin tradición -sin «espesor temporal»-. Pero el rigor de tal afirmación no lo condujo a un error de juicio que hubiese impedido observar las diferencias entre unas y otra: "No le ha ocurrido dudar al pueblo argentino que es un momento de la evolución secular de una raza insigne, la raza española. Mas por lo mismo distinguen muy bien entre raza española y la España contemporánea"15 -advertía Ortega (Ortega y Gasset, VII, p. 672)

El sustrato común era la garantía de una identidad incipiente que debía completarse sin renunciar a la diversidad de destinos de cada nación: "Porque España y Portugal y las Repúblicas del Sur y del Centro de América no llegarán a realizar su labor en la Historia sin que todas sientan al unísono esta misión como una aspiración redentora de hermandad y de igualdad"16 (Ortega y Gasset, 1915, I, p. 872).

Este planteo era solidario de su concepción de la historia y de la historicidad misma del ser humano. En Las Atlántidas (1924) la noción de «horizonte histórico» anima a imaginar cuál sería la trayectoria futura de una determinada sociedad sobre la base del conocimiento de sus íntimas preocupaciones, pero como ellas son, a su vez, la respuesta a las condiciones particulares en que se desenvuelve, la conclusión obligada a partir de aquellas premisas nos remite a la elaboración de un pensamiento original, radical y circunstanciali- 
zado. Será «original» porque contempla las variaciones, «radical», pues intenta responder al sentido de la existencia y "circunstancializado», ya que se va construyendo en la trama de lo concreto y cotidiano. El intento posterior de Leopoldo Zea de elaborar una «filosofía latinoamericana» bajo la impronta orteguiana va en esa misma dirección ${ }^{17}$. Otro tanto cabe decir de Eduardo Nicol, quien desde el exilio mexicano "insiste en el hecho de que no pudo constituirse una filosofía nacional en los países hispanoamericanos por el simple hecho de que las naciones mismas todavía no se habían constituido". Y agrega, "con la independencia se rompió la comunidad política, pero no la cultural”, (De Llera, 2004, pp. 81-82) y en consecuencia, sólo desde la raíz hispanoamericana es viable un pensamiento que espeje la identidad latinoamericana.

Lamentablemente, el país abierto y fervoroso que había recibido a Ortega en su segunda residencia, en 1928, había cambiado radicalmente en 1939, ocasión de la tercera y última visita. No sólo porque la cultura filosófica había crecido y se había desarrollado por el contacto directo con filósofos europeos -en especial alemanes- sino porque el clima bélico de la península se había trasladado a estas costas. La invitación a "tomar partido" en cuestiones de política española contaminaba todas las relaciones personales y Ortega padeció aquí tres años de exilio sin que su mensaje pudiera ser genuinamente comprendido. La frustración de que sus empresas editoriales no pudieran trasladarse a la Argentina, la falta de interés en concederle una cátedra universitaria y los problemas con el diario La Nación, con el cual ya no colaboraría, junto con otras penurias más personales ${ }^{18}$, representaron el ocaso de su influencia viva en la marcha espiritual del país.

Hubo que esperar hasta la década siguiente para que los pensamientos germinales de Ortega pudieran florecer en algunas cabezas argentinas. Tal fue el caso de César Pico, quien ocupó la cátedra de Sociología en la Universidad Nacional de La Plata y escribió en la Revista Sol y Luna un artículo titulado "Hacia la Hispanidad", en el que intenta establecer una analogía entre la unidad histórica y cultural de Europa y la noción de Hispanidad como una ultranación para los pueblos iberoamericanos, apoyándose en conceptos de Ortega. Dice textualmente:

Lo que es Europa para las naciones europeas, es la hispanidad para los hispanoamericanos. Sin los ingredientes europeos, las naciones de Europa perderían, como dice Ortega, las dos terceras partes de sus vísceras; y sin los ingredientes ibéricos las naciones de Hispanoamérica quedarían casi totalmente evisceradas (Pico, 1943, p. 137).

Paralelamente, en el centro de América, José Gaos, discípulo de Ortega pero radicado en México como consecuencia de la Guerra Civil española hablaba de un «pensamiento de lengua española» 19 y contribuía a lo que se llamó el «proyecto de normalización» de la filosofía latinoamericana en conjunción con el filósofo hispano-argentino Francisco Romero. ${ }^{20}$

Otro autor argentino, que frecuentó a Ortega durante su tercera residencia en Buenos Aires fue Máximo Etchecopar; abogado y diplomático, pero dotado también de una prosa cuidadosamente elaborada, en el libro Esquema de la Argentina (1956) remite en varias ocasiones a páginas de Ortega y en especial a los ensayos sobre la Argentina. Insiste, en 
un libro posterior titulado El fin del Nuevo Mundo, al igual que lo había hecho antes Pico, en la posibilidad de una gran patria hispanoamericana, reunida en torno al concepto de "elasticidad social":

Pero en uno y otro caso la solidaridad del gran cuerpo americano se pondría de manifiesto en lo que Ortega llama «la elasticidad social». Cada nación americana no estaría, pues, incomunicada herméticamente con su vecina soberana, sino que todas se comunicarían por dentro y por debajo a través del elástico vínculo, producto él de esa unidad mayor, consustantiva y preexistente, a que nos estamos refiriendo (Etchecopar, 1984, p.193).

Jaime Perriaux, uno de los fundadores de la Institución Ortega y Gasset, abogado y funcionario público, dedicó parte de su esfuerzo intelectual al esclarecimiento de la historia argentina mediante el empleo de algunas ideas de Ortega, en especial, las que le permitirían encontrar una clave a las secuencias de bienestar y de zozobra, de esperanza y de frustración, que cíclicamente regulan el péndulo de los acontecimientos de nuestra historia. Curiosamente, cierra su libro Las generaciones argentinas (1970) con un párrafo en el que invoca las mismas ideas transnacionales que despertaron en Pico y Etchecopar los textos orteguianos:

Y hay generaciones cuyo destino consiste en romper el aislamiento de un pueblo y llevarlo a convivir espiritualmente con otros, integrándolo así en una unidad mucho más amplia, metiéndolo, por decirlo así, de su historia retraída, particular y casera, en el ámbito gigantesco de la historia universal (Perriaux, 1970, p. 79).

En suma, la preocupación por la identidad nacional que habían expresado los escritores y periodistas de la década del treinta -argumentando a partir de una dura reacción frente a la sinceridad y al realismo del panorama espiritual que había descripto Ortega- dejaba paso en los sesenta y los setenta a su estudio científico (histórico, político y sociológico) todavía guiado por muchos conceptos orteguianos y abierto a una mirada que inscribía a la Argentina en el contexto de las naciones del sur de América.

Quien más lejos llegó en la intuición de una identidad latinoamericana a partir de las reflexiones del español fue José Luis de Imaz. Graduado de Licenciado en Ciencias Políticas y Diplomáticas por la Universidad del Litoral y de Doctor en Derecho y Ciencias Sociales por la Universidad de Buenos Aires, realizó estudios de posgrado en Francia. Alcanzó el grado de Investigador superior de Conicet y fue designado Profesor Emérito de la Universidad Católica Argentina -donde fue Director del Departamento y del Doctorado en Sociología-, se desempeñó también como Director de Asuntos Universitarios del Ministerio de Educación y Cultura al comienzo de la década del noventa. El libro Sobre la identidad iberoamericana (1984) concentra sus pensamientos en torno al tema que nos ocupa.

En él, de Imaz vuelve sobre los ensayos argentinos de Ortega y comienza por ubicar esas reflexiones en el contexto del debate de ideas en el país. Sostiene que el ensayo sobre sociedad y costumbres, que hizo su primera irrupción promediado el siglo XIX, tuvo en el 
Facundo de Sarmiento su expresión paradigmática. Pero el positivismo posterior anuló la inocencia de aquellas observaciones y habría que esperar hasta la llegada de las influencias neokantianas para rescatar la intuición como medio de conocimiento. En esta dirección

Keyserling, Ortega y Waldo Frank -afirma de Imaz- son producto de un momento antipositivista y fautores de ese momento: deben ser entendidos en el contexto de los años 20: el de la revalorización de la intuición sensible, la independencia del espíritu frente a sus condicionamientos materiales, y la expectativa de arribar al meollo, prescindiendo de lo fenoménico (de Imaz, 1984, p. 296).

En su obra nos presenta una lista de notas que forman el estereotipo del argentino y que significan una actualización de aquellas que había notado Ortega. Merecen transcribirse las siguientes: Determinismo (fatalismo), otredad (división de la personalidad en planos no percibidos como contradictorios), acomodamiento (manipulación de la verdad), imitación (copia cultural), "la gana" (voluntad débil, imprevisión), monotonía (vida sin sobresaltos, curiosidades intelectuales ni exigencias del espíritu: la melancolía como sentimiento fuerte), mitomanía (constante referencia a construcciones mentales imaginarias e indispensables para vivir colectivamente; esta categoría incluye la incapacidad para un análisis objetivo y desapasionado de nuestras irreemplazables responsabilidades), sobreentendidos (son propios de una cultura que se expresaría mejor por símbolos y silencios que por la precisión de sus conceptos), y cultura de sentimientos (sobrevalorar lo emocional en detrimento de lo racional).

Sobre esos cimientos precarios había que acomodar un proyecto trascendente que permitiera la estabilidad y la constancia de una comunicación existencial entre los pueblos iberoamericanos. Esa era la demanda de la hora y así lo plasmaba en un escrito del 1998:

Es redundante señalar que esta reflexión prospectiva -instalada en una de las dos alternativas que se vislumbran- pretende penetrar en el pellejo de esos políticos, diplomáticos y estadistas, que en definitiva, serán los autores de uno u otro proceso de integración. Pero el político -el que pondrá su firma- mira primero su suelo nutricio. El verdadero estadista -como recordaba Ortega- el hombre que le imprime su sello al siglo, el que crea instituciones, si quiere garantizar su continuidad debe hacer la revolución y la contrarrevolución al mismo tiempo (de Imaz, 1998, pp. 70-71).

Como queda dicho, las generaciones posteriores a la partida de Ortega de nuestras tierras revitalizaron su mensaje apropiándose de su vocabulario y de sus líneas de análisis sociológico. Esa labor continúa en nuestros días: el eco de las páginas de Ortega encuentra su espacio en las obras del Embajador Juan Archibaldo Lanús, quien abre la conferencia que dictara en la Universidad de Cambridge con el título "New global realities: a challenge to national identities in Latin America" citando al filósofo y a su teoría sobre los cambios 
y las crisis históricas, para justificar luego las dificultades que la globalización causan en nuestras repúblicas asentadas sobre la base de los valores e ideales consagrados en los procesos independentistas, y en particular, de la soberanía. La reversión hacia una totalidad integradora, como lo fueron reinos e imperios en la génesis de Europa, en el caso de Latinoamérica significa un ejercicio novedoso de recreación de la matriz cultural heredada de España y Portugal. Tanto en La Causa Argentina ${ }^{21}$ como en La Argentina Inconclusa ${ }^{22}$, su última publicación, la perspectiva orteguiana organiza muchas de sus ideas y canaliza las propuestas de identidad e integración decantadas por su pluma.

Nuevamente, entonces, el destino de Argentina es contemplado en unión indisoluble al del resto de los países sudamericanos. Como precisa Marta Campomar (2009):

Para Ortega, la búsqueda de autenticidad y de consolidación de una civilización propia implicaba dejar en segundo término los tonos y matices diversos, incorporando lo ibérico para dar carácter a otro tipo de vida latina. Éste había sido el desafío que Ortega dejó pendiente para las Bodas de Plata de la Cultural incluyendo en la ecuación a la Madre Patria España. Para este foro latinoamericano amplía el campo de las identidades que estaban haciéndose y deshaciéndose desde tiempos remotos, apuntando hacia una latinidad más mundializada (Campomar, 2009, p. 923).

Tampoco podemos omitir que la vigencia que el pensamiento de Ortega ha tenido en Argentina durante estas décadas se debe, en no menor medida, a la presencia de Julián Marías. Basta para vincular ambos acontecimientos, la entrañable amistad que unió a Marías con Perriaux y con Etchecopar, o simplemente leer los escritos del filósofo español que proyectan su mirada sobre nuestra sociedad. Entre otros, es imposible olvidar Esquema de nuestra situación (1970) ${ }^{23}$ y Sobre hispanoamérica con varias meditaciones argentinas (1973)24. De esta forma, también Marías multiplicó bajo la forma de conferencias e intervenciones periodísticas la mirada orteguiana depositada sobre los argentinos y su tarea histórica.

A modo de conclusión nos atreveríamos a señalar que el cambio de perspectiva sobre los ensayos argentinos de Ortega reveló, una vez más, nuestra dualidad constitutiva: por una parte, fue el reconocimiento post-mortem de sus aciertos, y por otra, precisamente, la puesta en acto, remozada, de la íntima convicción del argentino de que en el futuro todo se puede lograr, que el porvenir promisorio es capaz de activar las energías colectivas y ubicarnos, una vez más, en la cúspide de las naciones. La búsqueda de nuestra identidad todavía requiere de estímulos; es una cruzada moral más que étnica, prospectiva más que histórica, que señala su índole futuriza asociándose con el afán, la ilusión y el deseo. Quizás la mayor contribución de Ortega haya sido indicarnos, con sublime gesto, el objetivo y la trayectoria espiritual que los argentinos deberíamos perseguir. A nosotros nos cabe convertir aquellas profecías y adivinaciones pronunciadas desde un verbo interior en el pronóstico saludable hacia un destino compartido con los demás pueblos latinoamericanos. 


\section{Notas}

1. Ortega y Gasset, J. (2004-2010) Obras Completas, Madrid: Taurus/ Fundación Ortega y Gasset, volumen IV, p. 788. En adelante citaremos por tomo (en romanos) y página (en arábigos).

2. Si bien, como es sabido, antecedentes de dicha cuestión pueden rastrearse hasta la etapa de la independencia. No olvidemos las reflexiones de Simón Bolívar, en 1815, registradas en la Carta de Jamaica. 1815.

3. "Azorín: primores de lo vulgar", II, p. 291.

4. Cfr. Aras, R. (2004), “Ortega y los universitarios argentinos” en Ortega y Gasset en la cátedra americana, Buenos Aires: Grupo Editor Latinoamericano.

5. Así llama Francisco Romero a la tarea cultural desarrollada por Ortega en Argentina. Cfr. Romero, F., Ortega y Gasset y el problema de la jefatura espiritual y otros ensayos (1960), Buenos Aires: Losada.

6. Cfr. "Hegel y América”, II, 667-679.

7. Cfr. "Un discurso" (Revista España, 7 de mayo de 1915) I, 872: "Porque España y Portugal y las Repúblicas del Sur y del Centro de América no llegarán a realizar su labor en la Historia sin que todas sientan al unísono esta misión como una aspiración redentora de hermandad y de igualdad."

8. Problemas culturales”-Sobre la enseñanza clásica-”, I, 470.

9. "Por qué he escrito «El hombre a la defensiva»", IV, 305.

10. Tomo prestada esta expresión de Marta Campomar ("El perspectivismo americano de Ortega y Gasset", Revista de Occidente, N²76, 2004, pp. 153-186).

11. "Génesis e intención de Radiografía de la pampa" en EZEQUIEL MARTINEZ ESTRADA (1993), Radiografía de la pampa, Fondo de Cultura Económica: Buenos Aires, p. 450-451.

12. "Impresiones de España en América" (1917) VII, 671.

13. "Carta a un joven argentino que estudia filosofía” (1924), II, 468.

14. “Sobre los Estados Unidos” (1932), V, 44.

15. “Impresiones de España en América” (1917), VII, 672.

16. “Un discurso" (1915), I, 872.

17. Cfr. Daros, W.R. (2009), "La identidad social del hombre americano y argentino (L. Zea y J. Ortega y Gasset)" Disponible en: http://williamdaros.files.wordpress.com/2009/08/wr-daros-la-identidad-en-zea-y-ortega.pdf [Fecha de consulta: 06/06/2012]

18. Para un detalle pormenorizado del ánimo de Ortega en este período cfr. Máximo Etchecopar (1983), especialmente p. 114.

19. Tal el título del libro publicado en 1945.

20. Cfr. Muguerza, J. , “Ortega en Latinoamérica: el legado filosófico de José Gaos”, en Cerezo Galán, P. (2007), Ortega en perspectiva, p. 72.

21. Lanús, A. (1988), La Causa Argentina, Emecé: Buenos Aires.

22. Lanús, A. (2011), La Argentina Inconclusa, Ed. El Ateneo: Buenos Aires.

23. Marías, J. (1970), Esquema de nuestra situación, Columba: Buenos Aires.

24. Marías, J. (1973), Sobre Hispanoamérica con varias meditaciones argentinas, Emecé: Buenos Aires. 


\section{Referencias Bibliográficas}

Beorlegui, C. (2004). Historia del pensamiento filosófico latinoamericano. Una búsqueda incesante de identidad. Bilbao: Universidad de Deusto.

Campomar, M. (2009). Ortega y Gasset en la curva histórica de la Institución Cultural Española. Madrid: Biblioteca Nueva / Fundación José Ortega y Gasset.

(2004a). El pensamiento de Ortega, entre la dinámica del tiempo americana y la europea, en Ortega y Gasset en la cátedra americana. Grupo Editor Latinoamericano: Buenos Aires, p. 153.

(2004b). El perspectivismo americano de Ortega y Gasset, Revista de Occidente, $\mathrm{N}^{\circ}$ 276, pp. 153-186.

Carballo, C. A. (2010). Las ilusiones perdidas: ensayo sobre el siglo XX en la Argentina. Buenos Aires: Educa.

Cerezo Galán, P. (2007). Ortega en perspectiva. Madrid: Instituto de España.

Cruz Vélez, D. et.al. (1983). Ortega y Gasset y el destino de América Latina. Buenos Aires: Fundación Banco de Boston.

De Imaz, J. L. (1998). América del Sur: 2006, y el desafío de la globalización, Boletín de Lecturas Sociales y Económicas, Año 5, no 21, pp. 61-71.

(1984). Sobre la identidad iberoamericana. Buenos Aires: Editorial Sudamericana.

De Llera, L. (2004). Filosofía en el exilio: España redescubre América. Madrid: Ediciones Encuentro.

Gracia, J. E. y Jaksic, I. (1983). Filosofía e identidad cultural en América Latina. Caracas: Monte Ávila Editores.

Etchecopar, M. (1984). El fin del Nuevo Mundo. Buenos Aires: Corregidor. (1983). Ortega en la Argentina. Buenos Aires: Institución Ortega y Gasset.

Lanús, A. (2011). La Argentina Inconclusa. Buenos Aires: Ed. El Ateneo.

(1988). La Causa Argentina. Buenos Aires: Emecé.

Lasaga, J. (2006). Figuras de la vida buena. Madrid: Enigma Editores.

Marías, J. (1973). Sobre Hispanoamérica con varias meditaciones argentinas. Buenos Aires: Emecé.

(1970). Esquema de nuestra situación. Buenos Aires: Columba.

Medin, T. (1998). Entre la jerarquía y la liberación-Ortega y Gasset y Leopoldo Zea-. México: UNAM/FCE

Mora Rodriguez, A. (2005). La identidad latinoamericana: enfoque filosófico, Revista Comunicación, volumen 14, año 26, número 2, pp. 27-36.

Perriaux, J. (1970). Las generaciones argentinas. Buenos Aires: Eudeba.

Pico, C. (1943). Hacia la Hispanidad, Sol y Luna, No 9, pp. 115-145.

Zea, L. (1976). Filosofía y cultura latinoamericana. Caracas: Centro de Estudios Latinoamericanos "Rómulo Gallegos". 
Summary: Since his first trip to America, the Spanish philosopher Jose Ortega y Gasset had a" spiritual leadership "on the emerging thinking of the new overseas populations. In particular, the relationship with Argentina and the argentines allowed him to act as a catalyst in the question about the self and its mission in the world. The psychology essays on argentine people and their demand for "authenticity" to imagine a national and regional future placed him as an intellectual precursor to the problem of Latin American identity, whose influence over the minds of philosophers, sociologists, historians and scholars of these lands is allowed to observe to present.

Keywords: Argentina - de Imaz - Etchecopar - Gaos - identity - Marías - Latin America Ortega y Gasset - Pico - Zea.

Resumo: Desde a sua primeira viagem a América, o filósofo espanhol José Ortega y Gasset exerceu uma "chefatura espiritual" sobre o pensamento incipiente dos novos povos transatlânticos. Em especial, a relação com a Argentina e os argentinos lhe permitiu atuar como um agente catalisador na interrogação respeito ao próprio ser e sua missão no mundo. Os ensaios de psicologia do argentino e sua demanda de autenticidade à hora de imaginar um futuro nacional e regional o situam como um intelectual precursor no problema da identidade latinoamericana, cuja influencia sobre as mentes de filósofos, sociólogos, historiadores e literatos destas terras se deixa observar até nossos dias.

Palavras chave: Argentina - de Imaz - Etchecopar - Gaos - identidade - Marias - Latinoamérica - Ortega y Gasset - Pico - Zea. 